\title{
USE OF SEX PHEROMONES IN FRUIT PEST BIOCONTROL
}

\author{
D.M. SUCKLING ${ }^{1}$, A.R. GIBB ${ }^{1}$, G.M. BURNIP ${ }^{1}$, S.M. PAWSON ${ }^{1}$ and N. DeLURY ${ }^{2}$ \\ ${ }^{1}$ Horticulture and Food Research Institute of New Zealand Ltd. PO Box 51, Lincoln \\ ${ }^{2}$ Agriculture Canada, Summerland, British Columbia, Canada
}

The pheromone of a biological control agent, Ascogaster quadridentata Wesmael (Braconidae), of codling moth (Cydia pomonella L.), was used for the first time to explore the value of this new tool in fruit pest management. Traps for this egg parasitoid $(n=3)$ and pest $(n=3)$ were operated in a block of organic apples in Canterbury for two seasons, and trees $(n=10)$ were banded to collect prepupal larvae. Catches of the parasitoid in 1998-99 were adequate to compare the synchrony of the parasitoid with pest phenology, and showed that both were present from late October until midMarch. Pheromone traps for biological control agents can also offer detection of the presence and abundance of the agent, including the effectiveness of conservation biocontrol measures, such as habitat manipulation using floral food sources. Further work is in progress to develop applications of pheromones for biological control agents.

\section{ESTABISHMENT OF FORESTRY AND TREE PESTS IN NEW ZEALAND}

\author{
T.M. WITHERS and M. KAY
}

\section{Forest Research, Private Bag 3020, Rotorua}

This past year has seen the establishment in New Zealand of two exotic leaf-mining Lepidoptera from Australia: the blackbutt leaf miner, Acrocercops laciniella (Meyrick) (Gracillariidae), and the Banksia leaf miner, Stegommata sulfuratella Meyrick (Lyonetiidae). That both these insects were discovered during inspections of high risk environments (those surrounding Auckland Airport and the Port of Auckland) andshare a biology of a leaf-mining habit, suggests that an entry pathway remains open. Examination of insect pest establishments in the forestry sector in New Zealand over the last century shows that the overall rate of establishment is constant but varies for different insect guilds and origins. Forest insects establishing here from the northern hemisphere are primarily sapsuckers, some wood-borers, and very few defoliators. However, Australian insects from all three guilds continue to arrive and establish here. In the last ten years, Australian leaf-mining Lepidoptera, leaf-feeding Coloeptera and sap-sucking psyllids have been the most common successful invaders. Apart from the acknowledged ability of insects to fly here from Australia, this evidence suggests there is movement of contaminated Australian foliage into New Zealand. All Australian flora growing in this country is therefore under increasing biosecurity risk while this pathway remains open. 